\title{
Compaction and mechanical properties of soils compacted in the gyratory compactor
}

\section{Propiedades de compactación y mecánicas de suelos compactados en el compactador giratorio}

Natalia Pérez García

Mexican Transportation Institute, México

nperez@imt.mx

\section{Paul Garnica Anguas}

Mexican Transportation Institute, México

pgarnica@imt.mx

Delwyn Fredlund

Golder Associates, Canada

unsaturatedsoil@yahoo.com
Miguel Angel Reyes Rodríguez

Universidad Benemerita de Puebla, Mexico

miguelsl@msn.com

\section{Humberto García Cruz}

Universidad Autonoma de Chihuahua, Mexico

hgcbeto@hotmail.com

\section{Rodrigo Pérez Luis}

Instituto Tecnologico de Oaxaca, Mexico

rpl1986@hotmail.com

Fecha de recepción: 26 de noviembre de 2015 / Fecha de aprobación: 22 de abril de 2016

\section{RESUMEN}

En este artículo los autores presentan resultados de curvas de compactación de suelos finos que fueron determinadas con un compactador giratorio. Se muestra cómo varía la curva de compactación dependiendo de las variables controladas en el equipo giratorio durante la compactación (presión vertical, ángulo de giro y velocidad a la que se aplican los giros). Se llevaron a cabo comparaciones entre las curvas de compactación obtenidas por métodos tradicionales y las obtenidas con el compactador giratorio, encontrándose que la curva de compactación Proctor estándar se puede obtener si el suelo colocado en el equipo giratorio se densifica con 200 giros, con 1.25 grados de inclinación del molde y si se aplica una presión vertical de $200 \mathrm{kPa}$.Con respecto a la curva Proctor modificada, ésta no se logró obtener para ningún suelo con la combinación de variables estudiadas, al parecer se requiere de una presión vertical mayor a $800 \mathrm{kPa}$ para alcanzar los pesos volumétricos secos de dicha curva. En la investigación también se estudió el efecto del tipo de compactación (dinámica y por medio del compactador giratorio) en el módulo de resiliencia y la resistencia en compresión simple de muestras compactadas en el óptimo, $2 \%$ debajo del óptimo y $2 \%$ por arriba del óptimo. Los resultados indicaron que ambos parámetros dependen del tipo de compactación cuando las muestras compactadas tienen un contenido de agua inferior al óptimo.

PALABRAS CLAVE: características de compactación, diseño de pavimento, compactador giratorio, módulo de resiliencia, compresión no confinada.

\begin{abstract}
The authors present a series of compaction curves obtained in fine-grained soils through use of a gyratory compactor. The effect on compaction curves of variables such as vertical pressure, angle of gyration, and speed of gyration is shown. The curves obtained with the gyratory compactor were compared with those obtained using traditional methods of compaction (Proctor standard and modified compaction). It was observed that the standard compaction curve can be obtained with 200 gyrations, 1.25 degrees of angle of gyration, and a vertical pressure of $200 \mathrm{kPa}$. On the other hand, with the combination of variables studied in this research, modified compaction curves could not be reached. Tests were also performed to measure resilient modulus and unconfined compression strength on specimens prepared at optimum compaction conditions, $2 \%$ below the optimum and $2 \%$ above the optimum (for Proctor standard tests) using two methodsof compaction.The results indicate that unconfined compression strengths and resilient modulus are related to the compaction method when samples are compacted at water content below optimum.
\end{abstract}

KEYWORDS: compaction characteristics, pavement design, gyratory compactor, resilient modulus, unconfined compression. 


\section{INTRODUCTION}

Qualitycontrol of compacted materials has been one of the activities of major importance in the construction of earthwork projects. The process depends on the evaluation of fielddry density which is obtained after the material is compacted. The other parameter of importance is the maximum dry density measuredusing a standard test procedure (e.g., ASTM D698, ASTM D1557, AASHTO T99, or AASHTO T180).Even when standardtest procedures are followed,various authors have pointed out that impact compaction (Proctor tests) does not necessarily reproduce the same soil structure and compaction characteristics as the kneading process associated with field compaction equipment (Parsons et al., 2001; Holtz, 1990;Milberger and Dunlap 1966; Coyle and West 1956). Milberger and Dunlap (1966), and Ping et al.,(2003) stated that stress-strain curves differ ifspecimens are compacted with adynamic process in laboratory or if the curves are evaluated on undisturbed specimens. Lee et al.,(2007) evaluated properties such as unconfined compression, cohesion, and elastic modulus of samples compacted using different compaction methods. They found that specimens taken from field block samples show similar properties to specimens compacted in a gyratory compactor. It is not clear if the properties evaluated on specimens using the gyratory compactor and specimens compacted by traditional methods provide similar mechanical properties. It is important to develop accurate laboratory methods to better simulate the field compaction conditions since the goal of these methods is to adhere as closely as possible to field compaction conditions (Holtz, 1990, Ping et al., 2003).

The gyratory compactor has been shown to more closely simulate the compaction structure of hot asphalt mixes. This has led to the study of machines that better represent the field compaction of soils (Ping et al., 2003, Browne, 2006, Leet et al., 2007). The objective of this study was to evaluate the feasibility and applicability of the gyratory compactor as a means to: i.) evaluate the compaction characteristics of fine-grained soils, ii.) to evaluate the best set of variables to be controlled in the gyratory compactor in order to obtain the Proctor standard and modified compaction curves, and iii.) to compare results of resilient modulus and unconfined strength evaluated on specimens prepared by dynamic or gyratory compaction.

\section{MATERIALS AND EQUIPMENT}

\section{Materials}

The soils utilized in this study were collected in different regions of the State of Queretaro (Mexico).Index properties such as Atterberg limits (ASTM D 4318-10), specific gravity (ASTM D 854-10), and percent finer than 200 sieve (ASTM D 1140-00) were carried out; compaction properties were evaluated with the ASTM D698-12 and ASTM D1557-12 standards. Table 1 shows the properties of the studied soils.

\section{Gyratory Compactor}

The gyratory machine utilized in this research (distributed by IPC global) is a fully automated, servo-controlled, gyratory compactor which densifies the material by the simultaneous action of static compression and shearing action resulting from the mold being rotated through an angle about its longitudinal axis (Servopac manual, 1998). The variables that can be changed for compaction are: vertical pressure, angle of gyration, speed of gyration, and the number of gyrations applied to the specimen. The effect of these variables was studied in this research and the results are presented.

Table 1. Index properties and compaction characteristics

\begin{tabular}{|c|c|c|c|c|c|c|c|c|c|c|}
\hline \multirow{2}{*}{ Soilclass. } & \multicolumn{3}{|c|}{ Atterberglimits } & \multirow{2}{*}{$\mathrm{G}_{s}$} & \multirow{2}{*}{$\%$ fines } & \multirow{2}{*}{$\%$ sand } & \multicolumn{2}{|c|}{$\begin{array}{l}\text { Compaction characteristics } \\
\text { (ASTM D698-12) }\end{array}$} & \multicolumn{2}{|c|}{$\begin{array}{l}\text { Compaction characteristics } \\
\text { (ASTM D1557-12) }\end{array}$} \\
\hline & LL (\%) & PL (\%) & PI (\%) & & & & $W_{o p t}(\%)$ & $\gamma_{d \max }\left(\mathrm{kN} / \mathrm{m}^{3}\right)$ & $w_{o p t}(\%)$ & $\gamma_{d \max }\left(\mathrm{kN} / \mathrm{m}^{3}\right)$ \\
\hline $\mathrm{CH} 1$ & 66 & 25 & 41 & 2.61 & 86.0 & 14.0 & 30.0 & 13.32 & 20.5 & 15.70 \\
\hline $\mathrm{CH} 2$ & 69 & 24 & 45 & 2.56 & 87.0 & 13.0 & 33.5 & 12.60 & 24.0 & 14.86 \\
\hline $\mathrm{CH} 3$ & 70 & 28 & 42 & 2.65 & 79.4 & 20.6 & 34.0 & 12.58 & 26.5 & 14.58 \\
\hline $\mathrm{ML}$ & 44 & 33 & 11 & 2.56 & 87.0 & 13.0 & 32.0 & 13.00 & 24.5 & 14.60 \\
\hline SM & NP & NP & NP & 2.52 & 37.0 & 63.0 & 23.5 & 14.04 & 19.0 & 14.17 \\
\hline
\end{tabular}




\section{PROCEDURE TO EVALUATE COMPACTION CURVES WITH GYRATORY EQUIPMENT}

Samples of $2300 \mathrm{~g}$ of air-dried soil were mixed with a selection of molding water in the range of water contents where standard and modified compaction curves were measured. After water was mixed thoroughly with the soil, it was stored in a plastic bag for at least 16 hours. Following the storage, the compaction mold of the gyratory compactor was prepared by placing several vertical plastic strips around its interior to prevent the soil from sticking and to facilitate the removal of the sample without causing damage. The loose soil (2300 g) was placed into the mold (Figure 1a) and it was lightly tampered to accommodate the entire amount. The mold was then placed inside the gyratory compactor (Figure 1b) and the material was compacted in accordance with the selected combination of variables shown in Table 2.

After compaction, the specimen was extruded from the mold (Figure 1c) and dimensions and mass were recorded. The compacted specimen was then broken up to obtain three representative samples for water content measurement. The water content together with mass and dimensions of the specimen were utilized to determine the dry unit weight of the compacted sample.

\section{EVALUATION OF RESILIENT MODULUS AND UNCONFINED COMPRESSION}

Regarding the results of resilient modulus and unconfined compression, all soils were evaluated at optimum water content and maximum dry density (using the Proctor standard test). Only the results of $\mathrm{CH} 1, \mathrm{CH} 2$, and the ML soils are shown in this document due to limited space.

\section{Compaction of Specimens in the Gyratory Compactor}

The first step to compact the specimens was to select the variables to be set in the gyratory compactor in order to obtain the required density. The soil specimens were compacted using the following variables:ML and $\mathrm{CH} 2$ soils: 20 gyrations/minute, 1.25 degrees of gyration angle, 200 gyrations and $200 \mathrm{kPa}$ of vertical pressure. Soil CH1: 30 gyrations/minute, 1.25 degrees of gyration angle, 100 gyrations and $200 \mathrm{kPa}$ of vertical pressure.

After compaction in the gyratory compactor,the specimen has a height of $10 \mathrm{~cm}$ diameter and $20 \mathrm{~cm}$ height. It was the next ruded and trimmed to achieve $71 \mathrm{~mm}$ diameter and $144 \mathrm{~mm}$ height. These are the dimensions of test specimens (Figure $2 \mathrm{a}, 2 \mathrm{~b}$ and $2 \mathrm{c}$ ).The specimens were then measured and weighed before performing the testing.

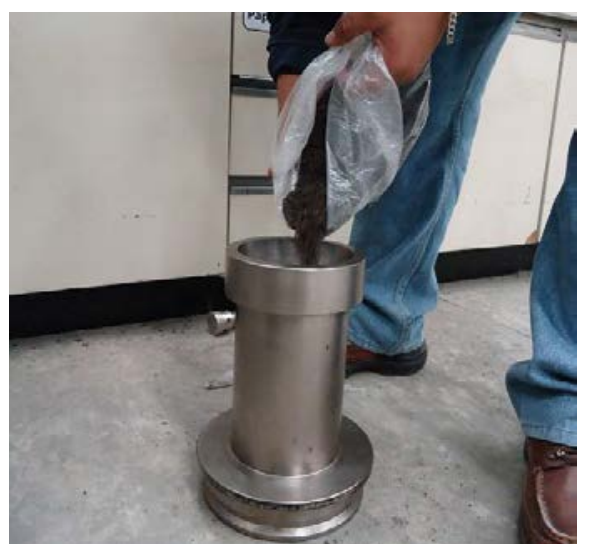

(a)

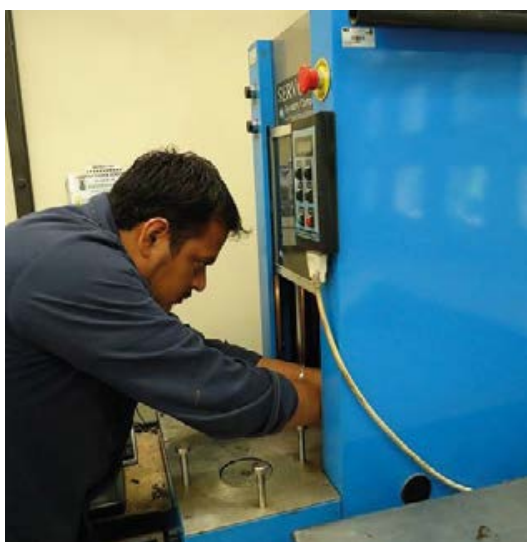

(b)

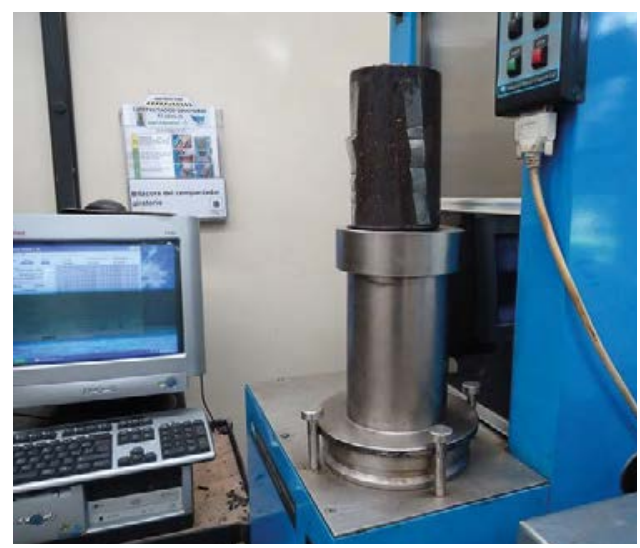

(c)

Figure 1. (a) Placing the loose soil into the mold; (b) Placing the mold inside the gyratory compactor; and (c) Sample after compaction

Table 2. Variables studied during the compaction

\begin{tabular}{|c|c|c|c|c|c|}
\hline Soil Type & Gyration rate, gyrations/minute & $\begin{array}{c}\text { Angle of gyration, } \\
\text { degrees }\end{array}$ & Vertical pressure, kPa & $\begin{array}{c}\text { No. of } \\
\text { gyrations }\end{array}$ & Replicates for each point \\
\hline ML & $10,20,30$ & 1.25 & $200,300,400,500,600$ & 500 & 3 \\
\hline SM & $10,20,30$ & 1.25 & $200,300,400,500,600$ & 500 & 3 \\
\hline CH1 & $10,20,30$ & $1,1.25$ & $200,300,400,500,600$ & 500 & 3 \\
\hline CH2 & $10,20,30$ & $1,1.25$ & $200,300,400,500,600$ & 500 & 3 \\
\hline CH3 & 30 & 1.25 & $200,300,400,500,600,800$ & 500 & 3 \\
\hline
\end{tabular}




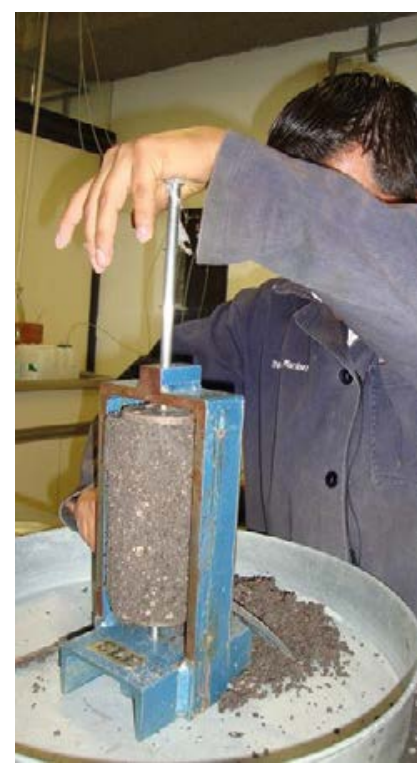

(a)

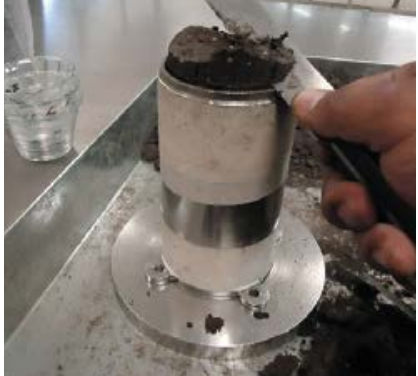

(b)

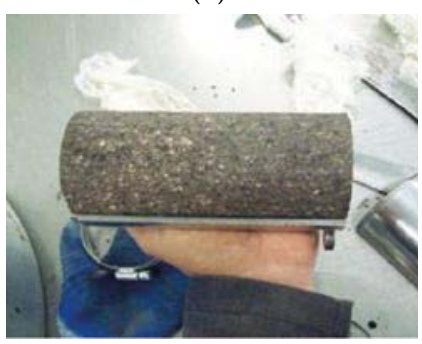

(c)
Figure 2. (a) Trimming the sample (dimensions after compaction: $100 \mathrm{~mm}$ diameter and $200 \mathrm{~mm}$ height); (b) The trimmed sample is placed inside a mold that has $144 \mathrm{~mm}$ height; the excess material was trimmed off; and (c) Sample of $71 \mathrm{~mm}$ diameter and $144 \mathrm{~mm}$ height.

\section{Samples Dynamically Compacted}

The soil was mixed with a specified amount of water in order toachieve the desired water content (optimum water content condition, $2 \%$ below optimum, or $2 \%$ above optimum). The material was then allowed to cure overnight in a sealed plastic bag. The mass of the soil required to attain the specified dry unit weight was weighed and compacted into the split mold $(71 \mathrm{~mm}$ diameter and $144 \mathrm{~mm}$ height) in eight layers with a rammer of 1 $\mathrm{kg}$ mass and dropped from a height of $30 \mathrm{~cm}$ (Figure $3 \mathrm{a}$ and $3 \mathrm{~b}$ ). The number of drops was calculated such that the maximum dry unit weight was achieved for each compacted layer of soil. After the final lift was compacted, the specimen was trimmed to give a uniform surface.The sample was separated from the mold (Figure 3c), weighed and measured.

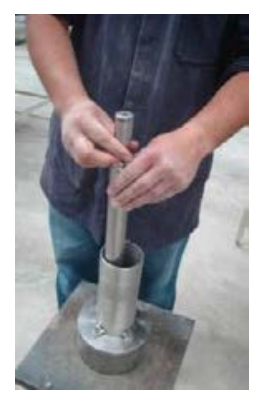

(a)

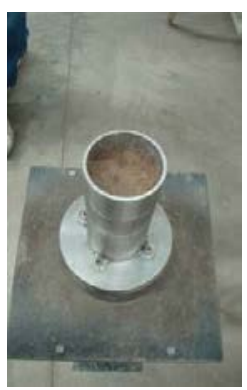

(b)

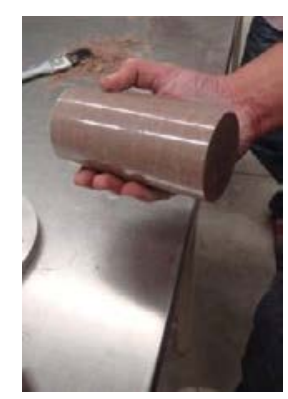

(c)
Figure 3. (a) Compaction with a rammer of 1 kg mass; (b) Specimen after the last layer was compacted; and (c) Specimen of $71 \mathrm{~mm}$ diameter and $144 \mathrm{~mm}$ height.

\section{RESILIENT MODULUS TESTING}

The resilient modulus tests were conducted in accordance with the NCHRP 1-28A test protocol for subgrade materials. The tests consist of applying a cyclic-haversine shaped load with duration of 0.2 seconds and a rest period of 0.8 seconds. During the test, 16 sequences involving different states of stress were applied. In each sequence, 100 load cycles were applied at a frequency of 5 $\mathrm{Hz}$; the last five cycles of each sequence were recorded and used to determine the resilient modulus, with the exception of sequence zero which is used as precondition of the soil sample.

\section{UNCONFINED COMPRESSION TEST}

The unconfined compression tests were performed in accordance with the ASTM D 2166-98a standard. The specimens were placed in a load frame and loaded at a rate of $1.2 \% / \mathrm{min}$. After the maximum load was reached, the soil specimen was broken up to give representative samples for water content measurements. The maximum value of compressive stress was reported as the unconfined compression strength.

\section{DISCUSSION OF RESULTS}

\section{Unit Weight of Compacted Samples in the Gyratory Compactor}

Five or six molding water contents were used at each vertical pressure for evaluation of the gyratory compaction curves. At least three replicate specimens were compacted at each molding water content. It should be noted that the gyratory compaction equipment does not directly report the dry unit weight of the soil, it was calculated by taking into account the height of the specimen (which was reported for every gyration), the diameter and mass of the specimen, and the water content which was determined at the end of the compaction test.

Figure 4 shows an example of the densification curves of three replicate specimens.This figure indicates that there are just small differences in the replicate specimens at the beginning of the compaction process. After 50 gyrations, all specimens tend to the same dry unit weight.The dry density at gyration 500 and the mean value of the three water contents were used to draw the compaction curves. 


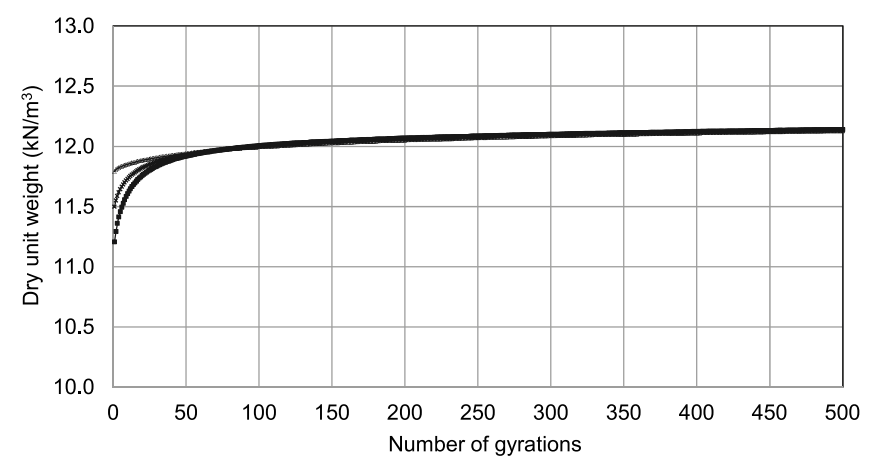

Figure 4.Evolution of dry unit weight during the compaction process

\section{Proctor and Gyratory Compaction Curves}

Figure 5 shows examples of the results of compaction curves obtained utilizing a rate of 30 gyrations/minute and a gyration angle of 1.25 degrees. The Proctor standard and modified compaction curves are shown for comparison purposes. From this figure it is observed that the standard compaction curve

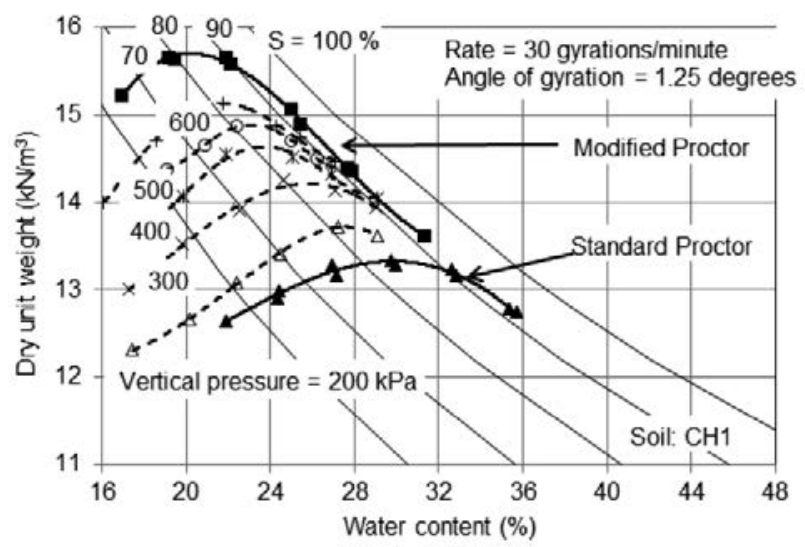

(a) Soil $\mathrm{CH} 1$

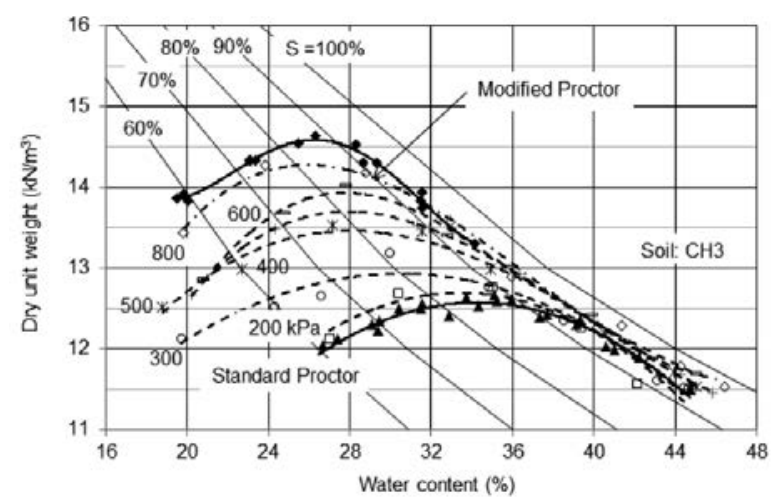

(c) Soil $\mathrm{CH} 3$ can be obtained with a particular combination of variables (e.g., 30 gyrations/minute, 1.25 degrees of angle of rotation and approximately $200 \mathrm{kPa}$ of vertical pressure), for the case of $\mathrm{CH}$ and ML soils (Figure 5b, 5c and 5d). However, for the SM soil, the compaction curves do not show the typical trend once the water content came close to the optimum water content (Figure 5e). The dry unit weights continued to increase even when the compaction water content was increased. This is likely due to the loss of water during the compaction process (Figure 5f). Figure 5 also indicates that in most cases the modified compaction curve was never reached. The exception was soil $\mathrm{CH} 3$ where a vertical pressure of $800 \mathrm{kPa}$ provided a compaction curve close to that of the modified compaction energy (Figure 5c).

\section{Variables that Influence the Evaluation of Compaction Curves with Gyratory Compaction}

Numerous variables can be varied to compact soil when using the gyratory compaction equipment. The following sections illustrate the effect of vertical pressure, angle of gyration, rate of compaction, and the number of gyrations.

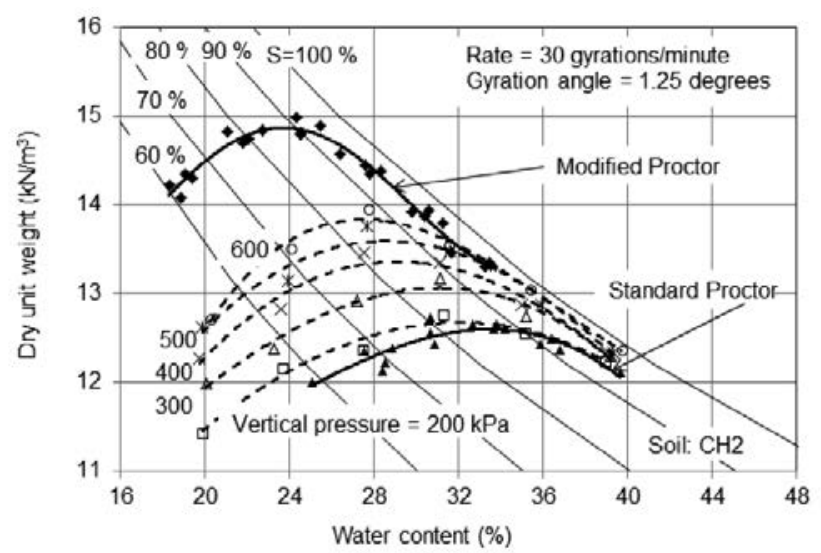

(b) Soil $\mathrm{CH} 2$

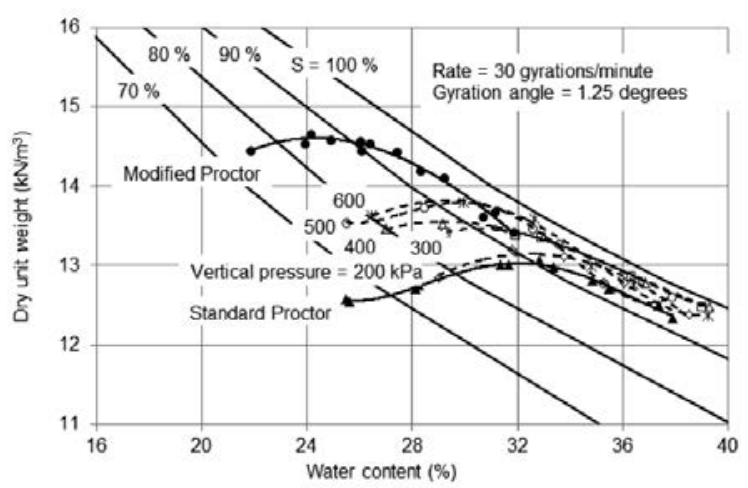

(d) Soil ML 


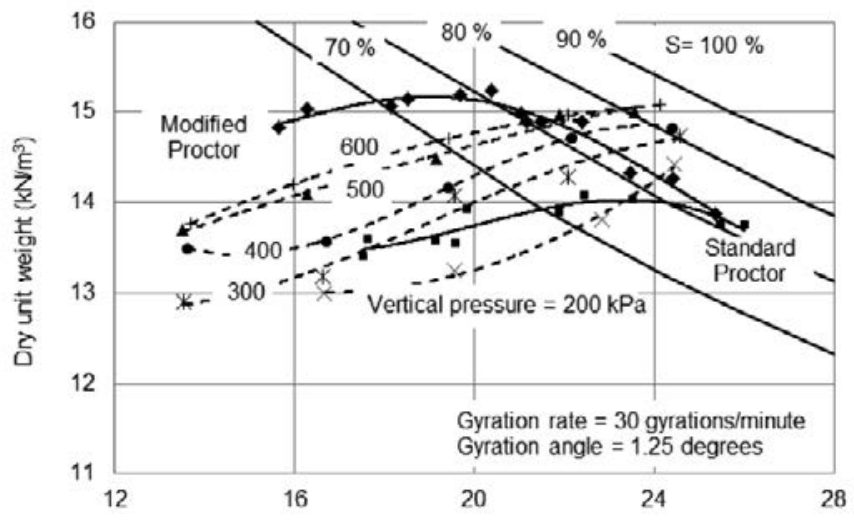

(e) Soil SM

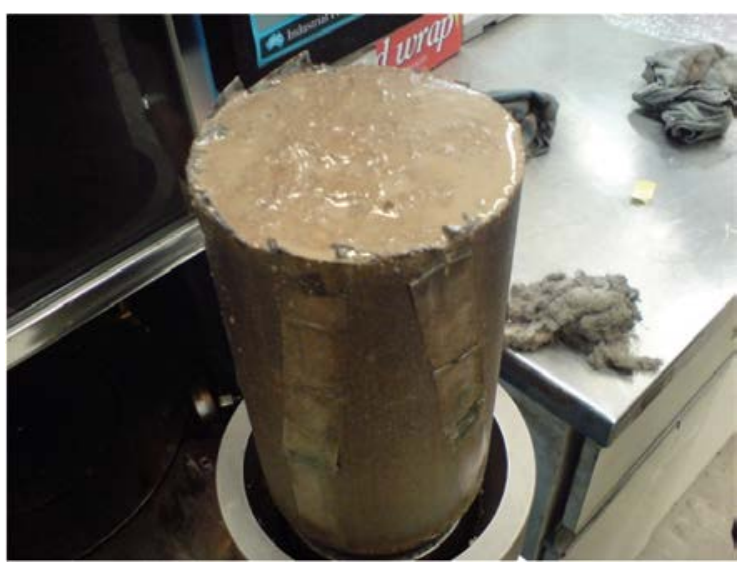

(f) Compacted sample at high molding water content

Figure 5. Compaction curves of tested soils and flow of water from sandy soil

\section{Number of gyrations}

The rate of change of the dry unit weight of the specimen is important during the first 50 or 100 cycles, however, eventually there is number of gyrations after which dry unit weight does not increase further. Thus, it can be concluded that compaction time can be reduced if samples are compacted with 100 gyrations (Figure 4).

\section{Rate of gyration}

The rates of gyration investigated in this research study were 10, 20, and 30 gyrations/minute. Figure 6 (corresponding to the $\mathrm{CH} 2$ soil) showsthat the velocity of compaction has a slight effect on the dry unit weight when compaction is on the dry side on the compaction curve. The velocity of compaction does not appear to have an influence on the wet side of optimum; this result is also observed in a plot of dry unit weight obtained for two different rates. The $\mathrm{R}^{2}$ values are close to 1 , which indicates that both rates of compaction provide similar results (Figure 7). The curves presented correspond to soil $\mathrm{CH} 2$, however, analogous behavior was observed for other soils (CH1, ML, and SM).It can be concluded that the soil can be compacted with 30 gyrations/minute(i.e., the largest rate studied) which will speed up the process.

\section{Angle of gyration}

The effect of the angle of gyration was studied for 1 and 1.25 degrees. For this variable, even when the change was not large, it is observed that an increase in this parameter produced slight differences in the compaction curve at $200 \mathrm{kPa}$
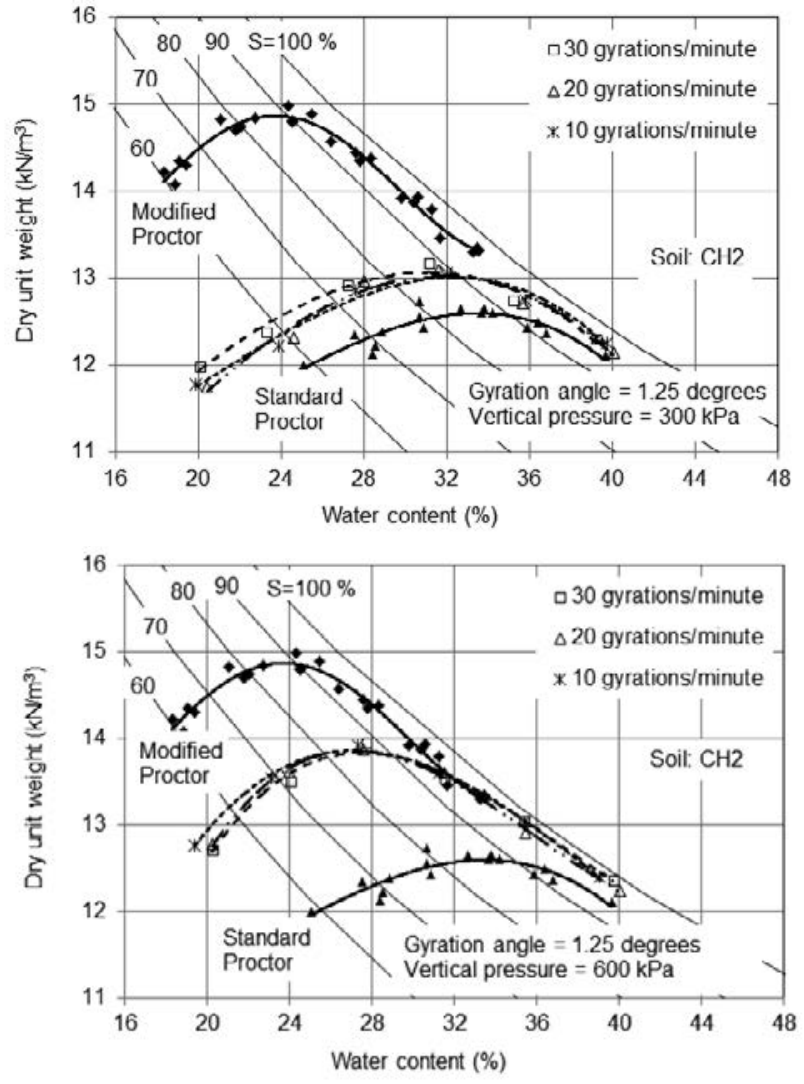

Figure 6. Effect of gyration rate on compaction curves

of vertical pressure (Figure 8a). However, for larger vertical pressures, the angle of gyration seems to have a more pronounced effect. The results indicate that the compaction energy can also be augmented by increasing the gyration angle (see Figure $8 \mathrm{~b}, \mathrm{c}$, and $\mathrm{d}$ ). 


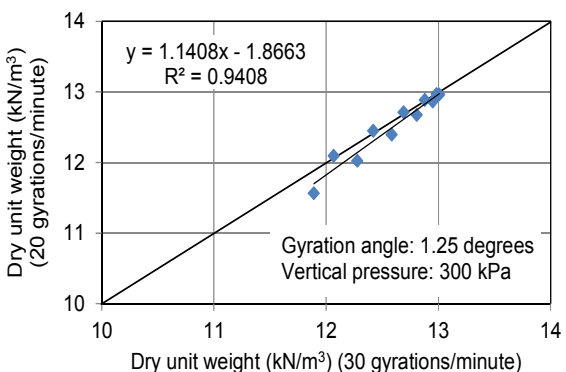

(a)

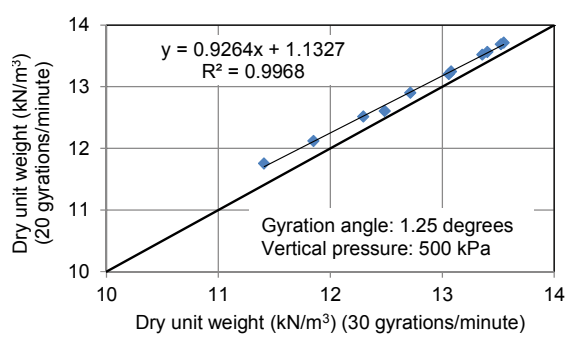

(d)

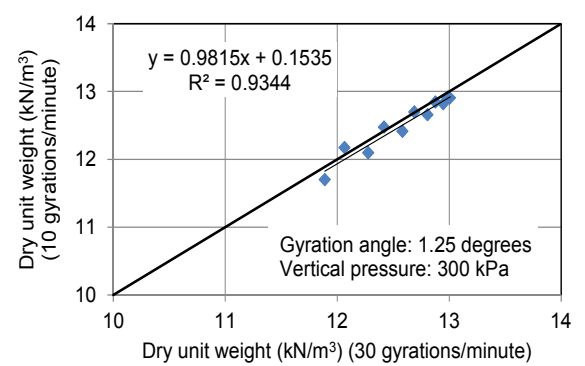

(b)

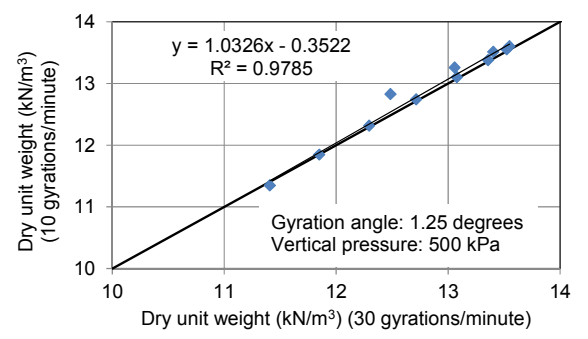

(e)

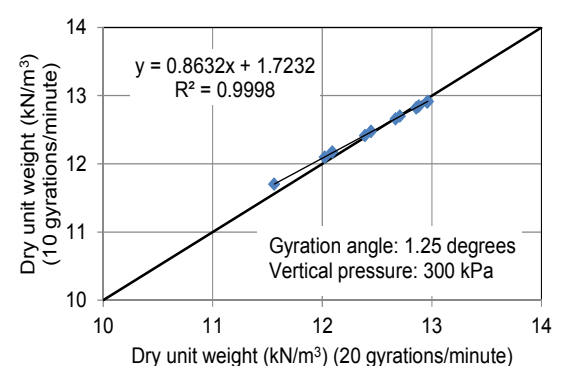

(c)

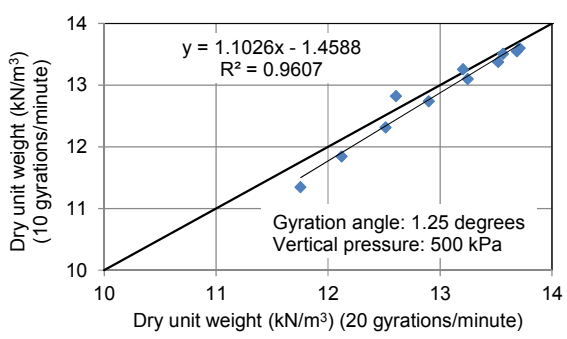

(f)

Figure 7. Comparison of dry unit weights evaluated at three different rates of gyration

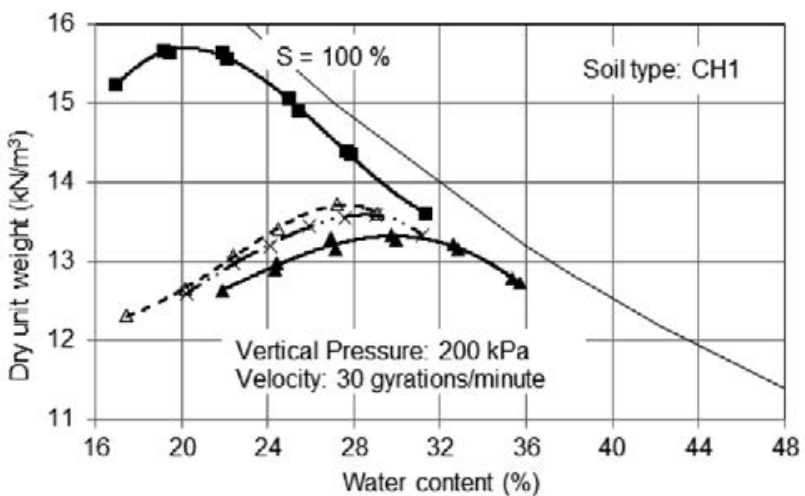

$\Delta$ Angle of gyration: 1.25 degrees $\times$ Angle of gyration: 1 degree

(a)

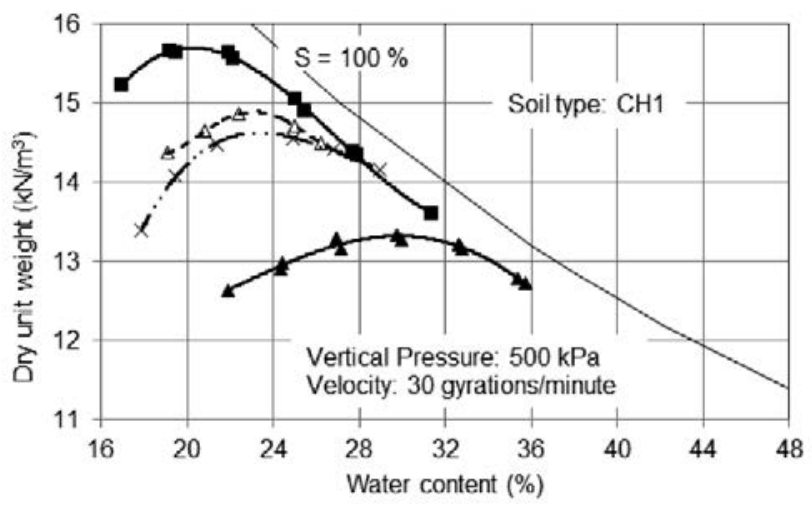

$\triangle$ Angle of gyration: 1.25 degrees $\times$ Angle of gyration: 1 degree

(c)

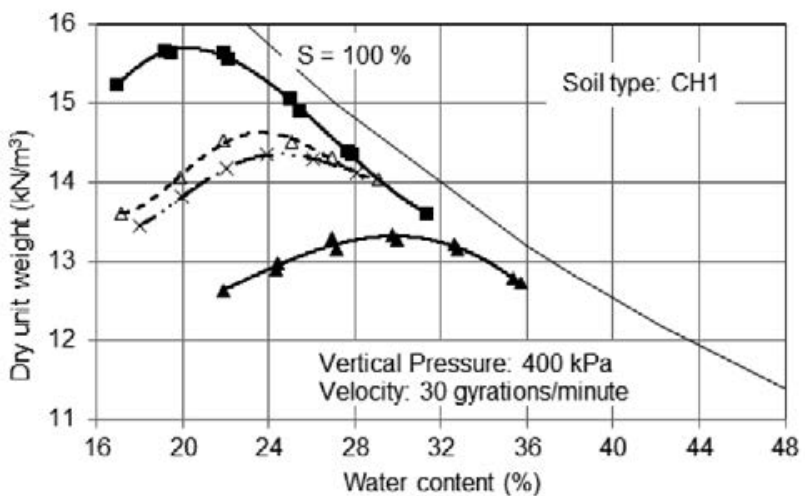

$\triangle$ Angle of gyration: 1.25 degrees $\times$ Angle of gyration: 1 degree

(b)

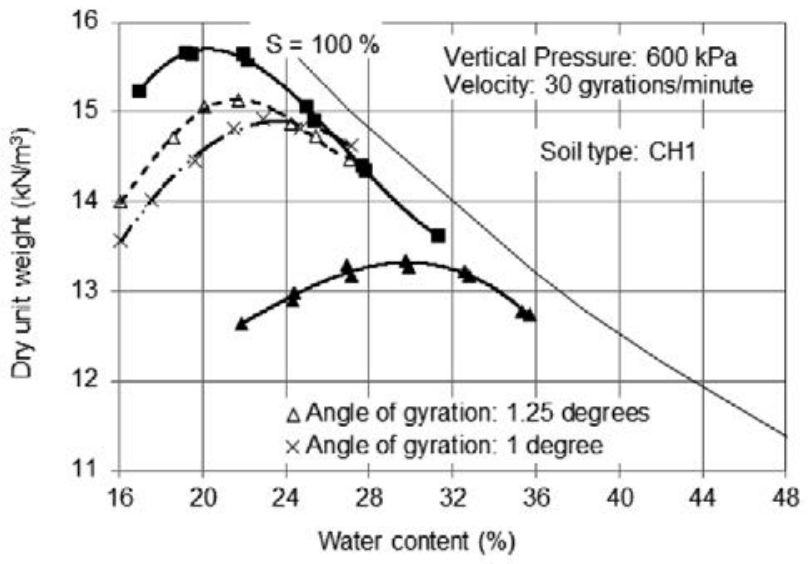

(d)

Figure 8. Effect of angle of gyration on compaction curves 


\section{Comparison of Mechanical Properties}

\section{Unconfined Compression}

Results from unconfined compression tests reveal that stressstrain curves of specimens compacted in the gyratory compactor for optimum water content and dry of optimum were always below to those compacted using dynamic compaction (Figure 9a and b). This may indicate that the gyratory compactor produces a loose structure which contributes to a lower strength. To verify this hypothesis, some compacted samples in the gyratory compactor were broken up and some subsamples were taken at the top, medium and bottom to measure the respective unit weights (Figure 10a). The results indicated that indeed, unit weight in the middle of the sample is lower than that obtained at bottom and top section of the sample (Figure 10b). It is likely that samples of considerable length (20 cm length) may not be uniformly compacted when the material is densified in one layer.

Figure 9c indicates that samples prepared above optimum water content have similar strengths regardless of the compaction method. Similar results were obtained for ML and $\mathrm{CH} 2$ soils.

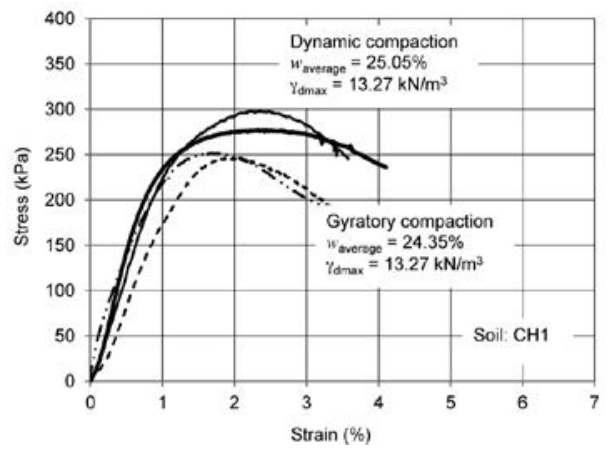

(a) $2 \%$ dry of optimum

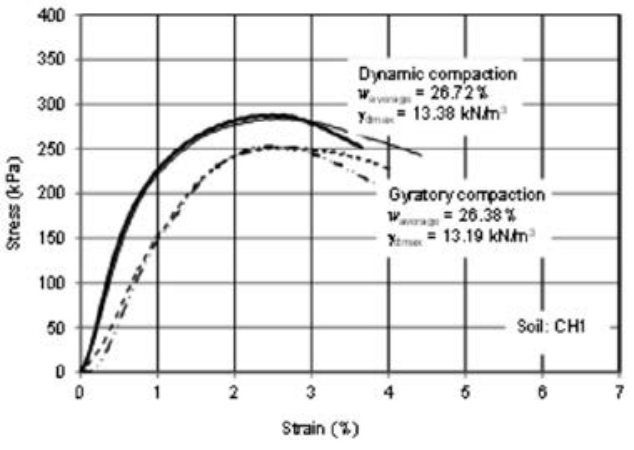

(b) At optimum water content

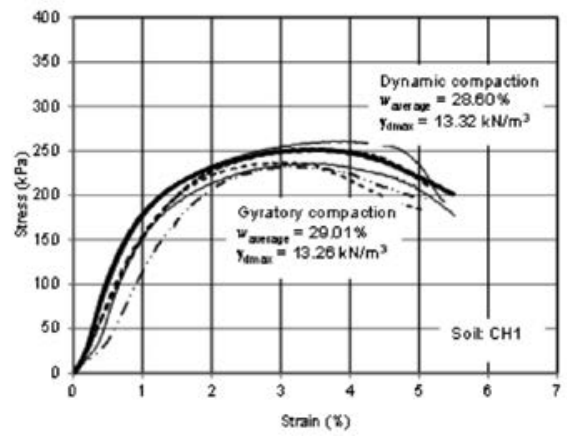

(c) $2 \%$ wet of optimum

Figure 9. Unconfined compression tests for $\mathrm{CH} 1$ soil

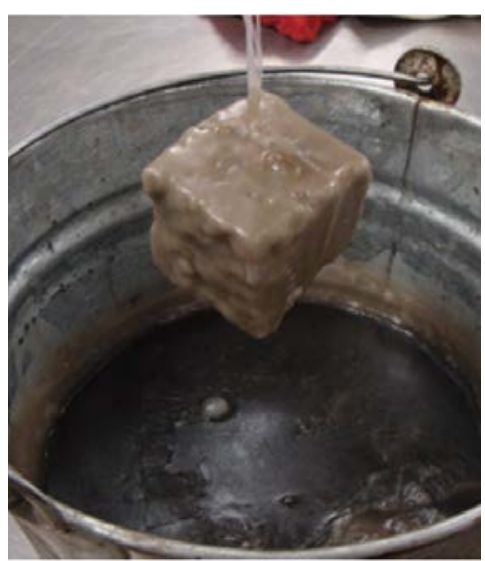

(a)

\begin{tabular}{|c|c|c|c|c|c|c|c|c|c|}
\hline $\begin{array}{c}\text { Sample } \\
\text { No. }\end{array}$ & Mass, $\mathrm{g}$ & $\mathrm{d}_{\text {prom }}(\mathrm{cm})$ & $\mathrm{h}_{\text {prom }}(\mathrm{cm})$ & $\gamma_{m}\left(\mathrm{kN} / \mathrm{m}^{3}\right)$ & $\begin{array}{c}\text { Subsample } \\
\text { No. }\end{array}$ & $\gamma m\left(\mathrm{kN} / \mathrm{m}^{3}\right)$ & $\gamma_{\text {maverage }}\left(\mathrm{kN} / \mathrm{m}^{3}\right)$ & $\mathrm{SD}\left(\mathrm{kN} / \mathrm{m}^{3}\right)$ & $\begin{array}{l}\text { Position of } \\
\text { subsamples }\end{array}$ \\
\hline \multirow{8}{*}{3} & \multirow{8}{*}{2291} & \multirow{8}{*}{10.14} & \multirow{8}{*}{19.85} & \multirow{8}{*}{14.02} & 1 & 14.38 & \multirow{3}{*}{14.27} & \multirow{3}{*}{0.11} & \multirow{3}{*}{ Top } \\
\hline & & & & & 2 & 14.26 & & & \\
\hline & & & & & 4 & 14.16 & & & \\
\hline & & & & & 1 & 13.06 & \multirow{3}{*}{12.97} & \multirow{3}{*}{0.17} & \multirow{3}{*}{ Medium } \\
\hline & & & & & 2 & 12.77 & & & \\
\hline & & & & & 4 & 13.07 & & & \\
\hline & & & & & $\frac{2}{3}$ & 13.78 & \multirow{2}{*}{14.18} & \multirow{2}{*}{0.51} & \multirow{2}{*}{ Bottom } \\
\hline & & & & & $\frac{3}{4}$ & $\begin{array}{l}14.75 \\
13.99\end{array}$ & & & \\
\hline \multirow{9}{*}{4} & \multirow{9}{*}{2289.5} & \multirow{9}{*}{10.14} & \multirow{9}{*}{19.92} & \multirow{9}{*}{13.96} & 1 & 13.54 & \multirow{3}{*}{13.55} & \multirow{3}{*}{0.02} & \multirow{3}{*}{ Top } \\
\hline & & & & & 2 & 13.58 & & & \\
\hline & & & & & 3 & 13.53 & & & \\
\hline & & & & & 1 & 12.34 & \multirow{3}{*}{12.34} & \multirow{3}{*}{0.05} & \multirow{3}{*}{ Medium } \\
\hline & & & & & 2 & 12.39 & & & \\
\hline & & & & & 3 & 12.29 & & & \\
\hline & & & & & 1 & 13.10 & \multirow{3}{*}{13.42} & \multirow{3}{*}{0.67} & \multirow{3}{*}{ Bottom } \\
\hline & & & & & $\frac{2}{3}$ & 14.34 & & & \\
\hline & & & & & $\frac{3}{4}$ & $\begin{array}{l}12.79 \\
13.45\end{array}$ & & & \\
\hline
\end{tabular}

(b)

Figure 10. Measurement of volume to determine unit weight; (b) Measurements of unit weight of compacted sample and subsamples

\section{Resilient modulus}

Figures 11a through 11c show the resilient modulus results for the ML soil. These plots reveal that the resilient modulus values of dynamically compacted and gyratory compacted specimens vary some what when compacted below optimum. However, when they are prepared at optimum or above this value, the resilient modulus values are more similar for both methods of compaction.
Results for $\mathrm{CH} 2$ soil also indicate that this parameter depends on compaction type (Figure 11d and e). The values of this soil agree with the suggested behavior obtained in unconfined compression which indicates a looser structure for samples from the gyratory compactor. 


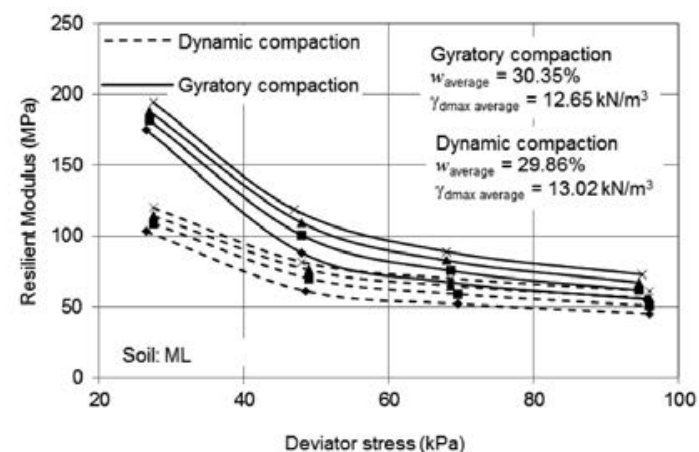

(a) $2 \%$ below optimum

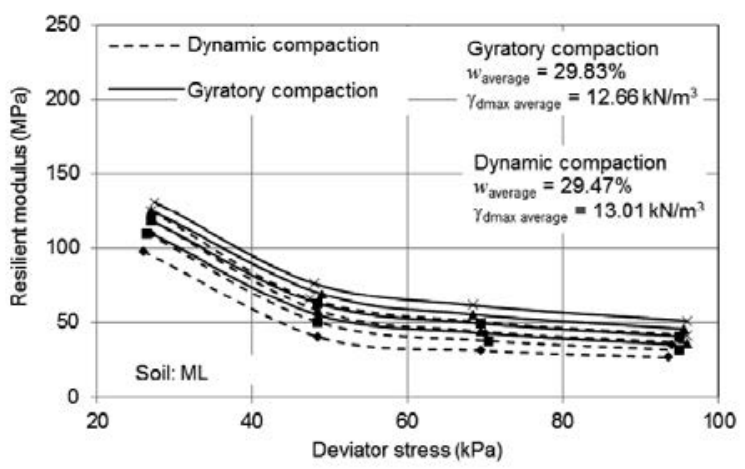

(b) At optimum

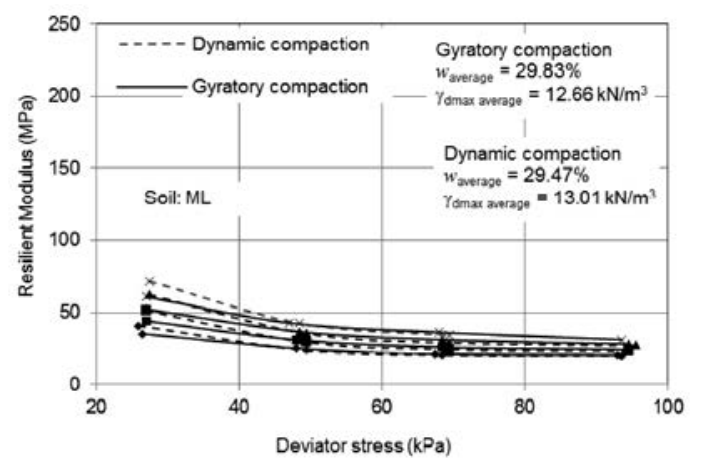

(c) $2 \%$ wet of optimum

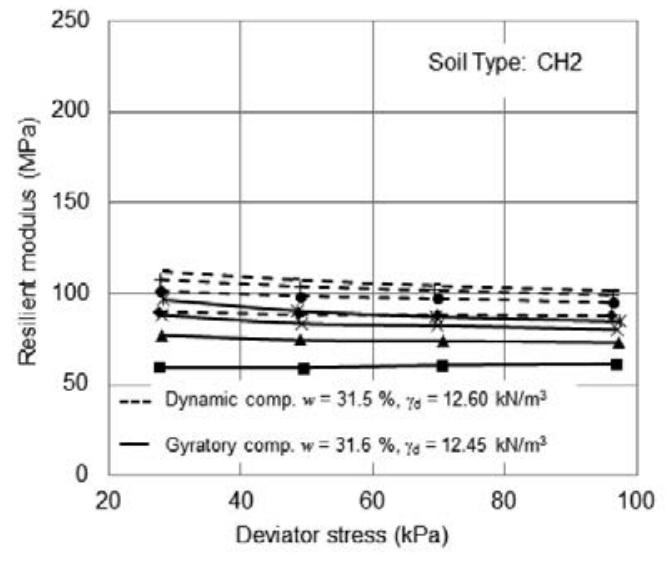

(d) $2 \%$ below optimum

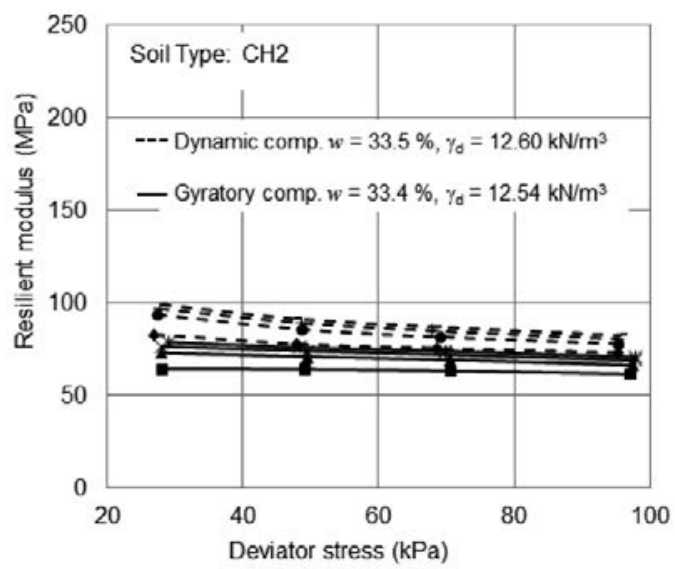

(e) At optimum 


\section{CONCLUSIONS}

The laboratory research study shows that the gyratory compactor shows promise as a device that can be used to measure compaction curves. However, it is important to assess the proper combination of variables that correspond to required compaction conditions. One of the advantages of the gyratory compactor is that the specimens produced can be directly used to determine stress-strain relationships. The specimens obtained from the gyratory compactor canhave a height/diameter ratio of 2 , butif this is not the case, it is possible to trim the specimens to the proper dimensions; however, care should be taken to ensure consistent unit weights along the length of the specimen. The gyratory compactor is an automated machine, thus the operator can preset each of the variables on the compactor and this can lead to specimens with less variation. The dynamic compaction procedure is manual and can result in human errors. It was found that unconfined compression strength measurements were lower for specimens compacted using the gyratory machine when the water contents were at optimum and $2 \%$ below optimum. When the compaction water content was $2 \%$ above optimum, the unconfined compression strengths were similar. The resilient modulus values are affected by the compaction method when the material was compacted below optimum water content while the values are similar when the samples are compacted above optimum. It was noted that the $\mathrm{CH} 2$ resilient modulus values for samples compacted in the gyratory machine were lower, which indicates a more deformable soil. This behavior agrees with the response observed in the unconfined compression tests.

\section{REFERENCES}

1. Browne, M.J. (2006). Feasibility of Using a Gyratory Compactor to Determine Compaction Characteristics of Soil. Thesis of Master of Science in Civil Engineering. Montana State University.

2. Coyle, H.M. \& West, E.C. (1956). Laboratory compaction of a silty clay to simulate field density curves. Thesis of Master of Science. Massachusetts Institute of Technology.

3. Holtz, R. (1990). Introduction. State of the art report. Guide to earthwork construction. Transportation Research Board. National Research Council. Washington, D.C.

4. Holtz, R. (1990). Compaction Concepts. State of the art report. Guide to earthwork construction. Transportation Research Board. National Research Council. Washington, D.C.

5. Industrial Process Controls Limited. 1998. PC-Based SERVOPAC Monitor. Reference Manual for Version 1.

6. Lee, K., Prezzi, M., \& Kim, N. (2007). Subgrade Design parameters from samples prepared with different compaction methods. Journal of Transportation Engineering. Vol. 3, No. 2. February 1. pp. 82-89.

7. Milberger, L.J. \& Dunlap, W. A. (1966). A gyratory compactor for molding large diameter triaxial specimens of granular materials. Research Report Number 99-2. Texas Transportation Institute.

8. NCHRP 1-28a. (2003). Harmonized Test Methods for Laboratory Determination of Resilient Modulus for Flexible Pavement Design. Transportation Research Board. Washington, D.C.

9. Parsons, R.L., Foster, D.H., \& Cross, S.A. (2001). Compaction and Settlement of existing embankments. Report No. K-TRAN:KU-00-8. University of Kansas.

10. Ping, W.V., Leonad, M., \& Yang, Z. (2003). Laboratory Simulation of Field Compaction Characteristics (Phase I). Research Report No. FL/DOT/RMC/ BB-890(F). Department of Civil and Environmental Engineering. Florida A\&M University. Florida State University. 